\title{
Effect of Group Counselling on the Psychological Adjustment of People Living With HIV/AIDS in Central Senatorial Zone, Cross River State, Nigeria
}

\author{
Mr Elizabeth G. Akpama (Ph.D) \\ Department of Educational Foundations \\ Faculty of Education \\ Cross River University of Technology \\ Calabar, Cross River State, Nigeria
}

Doi:10.5901/jesr.2013.v3v2p377

\begin{abstract}
This study examined the extent of difference to which people infected with HIV/AIDS adjust psycho-socially when exposed to group counselling as opposed to the one-on-one individual counselling, using the central senatorial zone of Cross River State, Nigeria as the study area. Two null hypotheses were formulated and data for their testing generated from a 15-items questionnaire developed by the researcher. The instrument was validated and tested for reliability by experts in measurement and evaluation in Cross River University of Technology, Calabar. The instrument was then used in generating data from 120 HIV/AIDS patients in three major government healthcentres in Obubra, Ikom and Yakurr local government areas/cluster of study area (60 males and 60 females). The ex-post facto research design and cluster, purposive and random sampling procedure was used. Data was analysed using the Pearson product moment correlation and independent t-test analysis procedures. It was revealed that: group counselling significantly relate to the psychosocial adjustment of people living with HIV/AIDS, and that the more the group counselling, the better the psychological adjustment of the people living with HIVIAIDS. More so, there was a significant difference between HIV/AIDS patients exposed to group counselling and those exposed to individual counselling. It was concluded that group counselling exerts higher and better significant affect on the psychosocial adjustment of people living with HIV/AIDS than individual counselling. Some counselling strategies were projected.
\end{abstract}

Key words: Adjustment, counselling, HIV/AIDS, group, individual, psychosocial, social

\section{Introduction}

Combating HIV/AIDS scourge has become the world's greatest challenges of the $21^{\text {st }}$ century. Millions of people globally are already infected with HIV. Daily, the scourge increases at alarming rate. HIV (Human Immune Deficiency Virus) destroys slowly the immune system of those infected. The virus which lives within the infected individual blossoms into full blown AID (Acquired Immuno Virus) if it is not carefully managed. The mode of HIV transmission has been mainly through sexual intercourse with an infected person; blood transfusion; contaminated infection needles; sharp infected objects (Delano, 2002; Odey, 2001; UNAID, 2001).

Oshotimehim (2003) noted that the epidemiological implications of HIV/AIDS in Nigeria include the following;

- The female are more at risk epidemiologically than their male counterparts

- $\quad$ Those infected and who fall between the age bracket of 15-21 are about $50 \%$.

- The most active reproductive age group is seriously affected. This group also falls into the category of persons the nation depends on for its greater tomorrow. This has serious implications for Nigerian economy, the physical health of the citizens, the social and psychological lives of those infected.

Akpama (2007) noted that a greater population of Nigerians are quite knowledgeable about HIV/AIDS scourge, several sensitization have also been carried out by health workers, researchers and non-governmental organizations and prevention and control as well as discrimination against people living with HIV/AIDS. Medical health workers as well as researchers have discovered certain coping drugs and strategies to ensure that the 
infected remain physically fit. Anti retroviral drugs have also been discovered to prevent HIV victims from developing full blown AIDS.

However, the thought of resting HIV positive often evoke many reactions. While some infected ones experience no problems in their adjustment, others find themselves muddled up with psychological and social problems such as depression, anxiety, moodiness, distressed emotionally. Some are in most cases discriminated upon or stigmatized at their places of work, family or the society. In most cases, it is not the infection that bothers those who are vulnerable but the stigma that is accompanied by psychological and physical problems. The management of people living with HIV/AIDS therefore requires both medical and psychotherapeutic interventions.

\section{The rational for counselling people living with HIV/AIDS}

Counselling is a professional assistance given to an individual with problems of maladjustment; disorder; emotional problems, etc. It is a learning oriented process which stresses more rational planning, problem solving, decision making, prevention of severe adjustment problems (Abdulkadir, 2010).

Akinade (2012) opined that counselling refers to a number of procedures used in assisting an individual in solving problems which arise in various aspects of his life. Counselling is a personalized relationship between a professionally trained counselor and individual seeking for help to be able to understand himself, his environment and also cope with his developmental problems. For any counselling situation, four elements are involved; the client (the individual who has a problem); the counsellor (who has expert knowledge and skills to assist the client); the problem which can occur in any area of the clients' life (the psychological problems experiences by the HIV/AIDS victim); and the environment in which the client's problem emanated from, and in which the client and the counsellor exist.

There are five stages in any counselling session: Referral; Diagnosis; Treatment; termination; and follow-up stage.

Referral: In the referral stage, the client is brought in contact with the counsellor. As is the case with this study, the HIV/AIDS infected person is brought to the counsellor either through his family, the church, other helping agencies or the hospital. The client it is also possible for the HIV/AIDS victim to seek help from the counsellor.

Diagnosis: A personalized relationship between the counsellor and the client is established during this stage. The counsellor establishes a rapport with the client. This is followed by a mutual trust. The empathic and rapport building, encourages the HIV/AIDS victim to open up and talk about his problem. The counsellor obtains a detailed account of the client's problem through psychological test, observation, diagnostic interviews, etc.

Treatment: The counsellor uses his theoretical orientation, professional skills and techniques to draw up a treatment plan which will be of assistance to the client.

Termination: This is a stage where the client ceases to go to the counsellor for therapy. This cessation takes place after a period of treatment. This is done in order to encourage the client to try to function on his own, using his newly acquired skills. Termination is systematically carried out in order not to leave a traumatic client in a traumatic state.

Follow-up: This is the counsellors' attempt to reassess the clients' condition after the 'client' withdrawal from the therapeutic session. In a situation where the client shows no remarkable improvement in his attempts to resolve his personal crisis, the client could be talked to resume for another therapeutic session. But where there is a remarkable improvement, the counsellor then terminates the counselling relationship permanently. HIV/AIDS counselling helps those infected to make realistic decisions about their lives; develop confidence in themselves; ensure that victims are not stigmatize by co-workers, family members and the society.

UNAID (2001) noted that the main aim of HIV/AIDS counselling is to:

1. Help to curb the negative reactions of people who are tested HIV positive.

2. Assist people living with HIV/AIDS to make realistic decisions which will help them to lead more positive lives.

3. Prevent the spread of HIV

4. Cope with the physical and social changes that may occur as a result of the infection.

5. Assist clients to achieve homeostasis. 
6. Reduce psychological stresses such as fear, pain, anxiety, depression, frustration, etc.

7. Assist clients to become socially accepted.

In order to achieve these counselling goals, therapeutic sessions can be carried out either on one-on-one basis (individual counselling).

\section{The individual counseling}

This is a one-on-one counselling relationship. Delano (2002) believed that the thoughts and feelings which the therapist holds towards a patient can change the behaviour of that patient. Oshotimehin (2002) emphasized that positive feelings and attitude from the therapist is often expressed in the empathic relationship which the therapist introduces to the patients. The HIV/AIDS patient is thus encouraged by the therapists' warm attitude to react positively to the treatment. Though a person to person relationship, the counsellor is able to enter into a personal and subjective relationship with the HIV/AIDS patient. In order to repose the confidence of the person living with HIV/AIDS, the counsellor offers no pretentions or defensive posture but makes the environment free for the vulnerable person to operate. The counsellor understands and accepts the client fully and freely. This personalized relationship is aimed at helping the HIV/AIDS patient to achieve the following:

1. To understand self in terms of personal abilities.

2. To gain an insight into the origin and development of emotional difficulties in order to take control over his feelings.

3. To alter maladaptive behaviour which may result from the thought of being HIV/AIDS positive.

4. To provide the patient with the knowledge and skills which will help him confront social inadequacies.

5. To help him understand and face the realities of his new state of being.

6. To help in developing decision making skills which will help him function well in his state of being.

7. To develop confidence in himself that he can function like others; that he is not a lesser being. Individual therapy provides confidentiality to the client (Akinade, 2012).

\section{Group counseling}

Group therapy is a therapy carried out between a therapist and a group of people sharing the same problem or condition. The composition of the group is usually four (4) to ten (10) people. The leader of the group is trained psychotherapist. Group therapy is a process using group interaction to facilitate understanding and self acceptance of individuals in a group. Member of the group are not randomly selected. For therapeutic session to be effective, the therapist considers the following:

The age range of group members: The success of any psychotherapeutic session depends on the age range of group members. Group members can feel free to bear their minds, if members fall within the same age bracket. Where adolescents and adults are merged together, it becomes difficult to attain therapeutic goals. This is because Nigerian culture does not permit a younger person to disagree with adults. This makes it necessary for vulnerable persons to be grouped within age brackets.

Group composition by sex (gender): Therapeutic sessions are most effective when group members who are of the same age bracket are of the same sex. The females will always feel free to discuss their minds especially when they are before fellow females. Men on the other hand will also not feel free to discuss intimately in a group comprised of both males and females.

Group counselling has some significant advantages which include:

1. Each individual feels understood and appreciated by those who suffer from the same problem.

2. It helps the patient to feel that he is not alone and so helps the patient to develop a sense of solidarity.

3. When members share their experiences, it helps them to understand their situation better.

4. Group members learn more about how they are perceived by other people.

5. It provides a forum for learning problem-solving skills.

6. It favours learning through listening to who others face the same problems.

7. It facilitates skills rehearsal in an accepting and understanding context. 
8. It reduces the feelings of guilt in the patient when he/she realizes that he/she is not an isolated individual and not different from others.

9. Group counselling helps to increase self-confidence, improve social skills and reduces tension among members who share similar problem.

10. It is time saving as the counsellor can address the problem of 4 to 10 people at a time rather than attending to individual one after the other (Akinade, 2012; Mebjosa, 2008 and Egbule, 2009).

\section{Psychosocial effects of HIV/AIDS}

The thought of testing HIV positive causes trauma to the victims. This trauma could be either psychological or social in nature. The victims are often occupied with thoughts of anger (why should it happen to them); fear of death; guilt of having to unavoidably pass it on to other; thoughts of how to fit into the social circles; how to cope with work; how to face family members; how to face employers; having to loose their jobs if their employers should discover their HIV status, etc.

Most people living with HIV/AIDS can not publicly acknowledge their status for fear of being stigmatized. Some would not dare to go to nearby hospitals for treatment neither would they go for counselling for fear of being stigmatized (Odey, 2004; Edu, 2012).

Ndama (2003), Cogan, Magongo \& Kganakga (2002) noted that people living with HIV/AIDS feel reluctant to introduce behaviours that will curb the spread of HIV because of the stigma attached to HIV/AIDS. For instance, an HIV man may feel reluctant to introduce the use of condom to his wife and other sex partners for fear of being stigmatized, but could discuss freely with others they known are equally infected. Employees who are vulnerable avoid the use of the health centres of their places of work for fear of being detected as being HIV positive and stigmatized. Such victims will not also risk to loose their jobs as most employers terminate their contacts with employees found to be HIV positive.

The family system is not also spared from the stigma of HIV. The Nigerian culture forbids promiscuity or sexual aberration of any kind. HIV/AIDS is often linked with indecency and immoral activities. An HIV positive person is therefore regarded as a disgrace to the family and the society.

Akpama (2007), Edu (2012) and Akintoye (1994) noted that where as an infected person may not feel free to discuss safety measures with the non-infected, they discus freely with those they have identified as sharing the same problem with them.

\section{The problem}

HIV/AIDS scourge has tremendous effect on the social and psychological lives of its victims. The infection itself is linked up with stigmatization and discrimination which leads victims to their early graves. Counselling people living with HIV/AIDS has become the best option for victims to resolve their psychological and social problem caused by the trauma of testing positive. As a result of the awareness of the importance of counselling to the people living with HIV/AIDS, there has been an influx of victims to hospitals and counselling laboratories, seeking for counselling sessions.

HIV/AIDS victims require medical treatment for physical healthy living as well as counselling to take care of their psychological and social problems. As a result of the increase in the population of HIV/AIDS victims, counsellors now face a greater challenge of having to attend to HIV/AIDS patients individually (one-on-one basis).

The problem of this study is therefore thus: since HIV/AIDS' victims experience similar psychological and social problems, they fall within the age brackets of either being an adolescent or adult, the victims are either female or male can group counselling be effective in addressing the psychological and social problems of these victims?

\section{Purpose of the study}

The purpose of this study is to determine: 
1. The rational for using group counselling on the psychological and social problems of people living with HIV/AIDS.

2. Whether there is any difference between the psychosocial adjustment of subjects exposed to group counselling and subject who are exposed to group counselling

\section{Research hypotheses}

1. There is no significant relationship between group counselling and the psychosocial adjustment of people living with HIV/AIDS.

2. There is no significant difference in the psychosocial adjustment of subjects exposed to group counselling and others exposed to individual counselling.

\section{Methodology}

\subsection{Research design}

Descriptive cross sectional research design was used for this study. This design was used to investigate the effect of group counselling on the psychosocial adjustment of people living with HIV/AIDS. The opinions of the victims were ascertained through the use of the questionnaire.

\subsection{Scope of the study}

This research study covered the geographical expression known as the central senatorial zone of Cross River State, Nigeria. This zone comprises of six (6) local government areas: Abi, Boki, Etung, Ikom, Obubra and Yakurr. Each of these local government areas has general hospitals and health centres located in all the communities. These health centres and general hospitals sections for HIV/AIDS positive known as heart to heart centres. These heart to heart centres are managed by health workers who are care givers and counsellors.

\subsection{Population of study}

This study covered all HIV/AIDS infected victims undergoing treatment in the heart to heart centres across the central senatorial zone of Cross River State, Nigeria. The Heart to Heart centre in each of the six local government areas was utilized for this study.

\subsection{Research sample and sampling procedure}

The study utilized a sample of 120 people living with HIV/AIDS. 3 local government areas were randomly selected for the study. The selected local government include: Ikom, Obubra and Yakurr. 40 people living with HIV/AIDS were randomly selected from each of the 3 local government areas. The cluster and random sampling procedures were used by the researcher to separate 20 males from 20 females in each of the selected local government areas. Purposive and accidental sampling technique was used to purposively select people living with HIV/AIDS from the Heart to Heart centres. Accidental sampling technique was also used by the researcher to administer questionnaire to only those present at the period of visit. 
Sample distribution of PLWHA by local government area and by sex in the central senatorial zone of Cross River State, Nigeria

\begin{tabular}{|l|l|l|l|l|l|l|}
\hline S/N & L.G.A & $\begin{array}{l}\text { Names of sampled heart } \\
\text { to heart centre }\end{array}$ & $\begin{array}{l}\text { Total number } \\
\text { of sampled } \\
\text { PLWHA }\end{array}$ & Males & Females & $\%$ \\
\hline 1 & Ikom & General Hospital, Ikom & $40(33.33 \%)$ & 20 & 20 & 16.67 \\
\hline 2 & Obubra & General Hospital,Obubra & $40(33.33 \%)$ & 20 & 20 & 16.67 \\
\hline 3 & Yakurr & General Hospital, Ugep & $40(33.33 \%)$ & 20 & 20 & 16.67 \\
\hline & Total & 3 & $120(100 \%)$ & 60 & 60 & 50.00 \\
\hline
\end{tabular}

\section{Research instrument}

A well structured questionnaire was the instrument used for data collection. A 15-items questionnaire was divided into 3 sections. Section 'A' measured the demographic and socio-economic status of the people with HIV/AIDS. Section 'B' measured the rational for group counselling on the psychosocial adjustment of people living with HIV/AIDS. While Section C measured the effect of group counselling and individual counselling on the psychosocial adjustment of people living with HIV/AIDS.

The research instrument was validated by an expert in measurement and evaluation. A four likert point scale was used for scoring the instrument. The positive items were allotted the following points: strongly agree (SA) 4, agree (A) 3, disagree (D) 2, and strongly agree (SD) 1. On the other hand, all items on the negative in composition had the reverse points as: strongly agree (SA) 1 , agree (A) 2, disagree (D) 3 , and strongly agree (SD) 4.

\section{Reliability of research instrument}

The instrument for the study was first subjected to a trial test for the purpose of establishing its reliability. The test-retest method was used to measure the consistency of the instrument. Ten respondents who were within the study population but who will not be used for the final study sample were randomly selected from the Heart to Heart centre in Ugep General Hospital and were used for the trial test. The questionnaire was administered to the group. Test retest estimate reliability was obtained by re-administering the same test to the same group of respondents within two weeks of interval. Data collected was statistically analysed to estimate the test-retest reliability coefficient of the variables. The result yielded high correlation coefficient.

\section{Data analysis and discussion of findings}

Generated data from field work were first prepared by coding/scoring to yield numerical data (mean scores (x) and standard errors (SD) that were used in data analyses. The prepared codes were stored in a data bank; it was from the data bank that data was extracted, summarized into means ( $x$ ) and standard deviation (SD), and then subjected to statistical analyses using the independent $\mathrm{t}$-test analytical procedures. The hypotheses and their statistical analyses in Tables 1 and 2 as follow;

$\mathrm{Ho}_{1}$ : There is no significant relationship between group counselling and the psycho-social adjustment of people living with HIV/AIDS. The dependent variable (y) in this hypothesis was the psycho-social adjustment of HIV/AIDS people while the independent variable ( $x$ ) was group counselling (uncategorized). In testing this hypothesis summarized data (from the data bank) that is mean $(x)$, standard deviations (SD), sum $\left(\sum x, \sum y\right)$, sums of squares $\left(\Sigma x^{2}, \Sigma y^{2}\right)$, and sums of products were subjected to statistical analysis using the Pearson products moment correlation coefficient ( $r$ ) procedure, and the result presented in Table 1.

$\mathrm{Ho}_{2}$ : There is no significant difference in the psycho-social adjustment of subjects exposed to group counselling and others exposed to individual counselling. The dependent variable in this hypothesis was the psycho-social adjustment of people living with HIV/AIDS, while the independent was the nature of counselling (categorized 
into group and individual). In testing this hypothesis (into means $x$, and standard deviations SD) from the data bank, was subjected to the independent t-test analytical technique, and the result presented in Table 2.

Table 1: Pearson product moment correlation coefficient analysis for the relationship between group counselling and the psycho-social adjustment of HIV/AIDS people. $\mathrm{N}=120$

\begin{tabular}{|c|c|c|c|c|c|c|c|c|}
\hline Variable & $\bar{x}$ & SD & $\begin{array}{l}\Sigma x \\
\Sigma y\end{array}$ & $\begin{array}{l}\sum x^{2} \\
\sum y^{2} \\
\end{array}$ & $\sum x y$ & Df & r-cal & p-val \\
\hline \multirow[t]{2}{*}{ Group counselling (x) } & 17.917 & 3.578 & 2150 & 15,232 & & & & \\
\hline & & & & & 15,659 & 118 & $0.20^{*}$ & .002 \\
\hline Psycho-social adjustment (y) & 19.317 & 3.628 & 2318 & 32017 & & & & \\
\hline
\end{tabular}

* Result significant at $\mathrm{p}<.05, \mathrm{df}=118$, crit $r=1.195$ (2-tailed)

Table 2: Independent t-test analysis of the difference in the psycho-social adjustment of HIV/AIDS people exposed to group versus other to individual counselling. $\mathrm{N}=120$

\begin{tabular}{llllll}
\hline Variable & $\overline{\mathbf{x}}$ & $\mathbf{S D}$ & $\mathbf{d f}$ & t-cal & p-val \\
\hline Individual: 60 & 18.500 & 3.128 & & & \\
& & & 118 & $4.295^{*}$ & .000 \\
Grouped: 60 & 20.933 & 3.078 & & & \\
Total: 120 & 19.716 & 3.103 & & & \\
\hline
\end{tabular}

* Result significant at $p<.05, \mathrm{df}=118$, crit $r=1.968$ (2-tailed)

From Table 1 , the calculated r-value of $0.207^{*}$ was found to be greater than the critical r-value of 0.195 needed for significance at 0.05 alpha level with 118 degree of freedom. With this result, the null hypothesis was rejected. This means that there is significant relation between group counselling and the psycho-social adjustment of people living with HIV/AIDS. Observation of the calculated $r$-value shows that it is positive, this implies that the more the group counselling, the better the psycho-social adjustment of these people living with HIV/AIDS.

From Table 2 the calculated r-value of $4.295^{*}$ was found to be greater than the critical r-value of 1.968 needed for significance at 0.05 alpha level, with 118 degrees of freedom. With this result, the null hypothesis was rejected. This means that there is significant difference in the psycho-social adjustment of subjects exposed to group counselling and others exposed to individual counselling. Furthermore, the mean scores of those exposed to group counseling were higher $(x=20.933, S D=3.078)$ than the scores of their counterparts exposed to individual counselling $\left(\mathrm{x}_{2}=18.50, \mathrm{SD}_{2}=3.128\right)$. This implies that those exposed to group counselling are better focused and more consistent in their responses and as such are more likely to adjust psychosocially than others exposed to individual counselling. Because they are somewhat inconsistent in their responses, such HIV/AIDS infested group are likely to adjust very effectively psycho-socially than individuals who discusses their problems with only the counsellor.

\section{Summary of findings}

These statistical analyses of the hypotheses of this research have proven to us the facts that:

1. There is significant relationship between group people living with HIV/AIDS. The more the counselling in groups the better they cope and adjust psycho-socially in their lives.

2. There is significant difference in the psycho-social adjustment of subjects, exposed to group counselling and others exposed to individual counselling. Those exposed to group counselling confessed (or assert) to adjust better, psycho-socially than others expose to individual counselling by their mean scores. 


\section{Discussion of results}

The statistical analysis of hypothesis one of this study have exposed the facts that there is significant relationship between group counselling and the psycho-socially in their lives. These revelations are in consonance with Edu (2012); Akindade (2012); Egbule (2009) who opined that when people with similar problems are brought together, it enhances effective therapy.

The statistical analysis of hypothesis two has also exposed us to the fact that the psychosocial adjustment of HIV/AIDS people who are counselled in groups differs significantly from the adjustment of their counterparts who are counselled individually. That those exposed to group counselling adjust better psycho-socially (mean = 20.933, $S D=3.078$ ) than others exposed to individual counselling (mean $=18.50, S D=3.128, t=4.295^{*}, p<.05$ ). These findings are in agreement with Akpama (2007); Cogan et al (2002) and Ndama (2003) who posited that there are more benefits to be counselled in groups than individually.

\section{Recommendations}

1. Following the increasing rate of spread of HIV group counselling is most efficient approach in counselling people with HIV/AIDS.

2. Group counselling should form an integral part of counsellors training on HIV.

3. Group counselling should be introduced in all hospitals, clinics and care centres where attention is given to people living HV/AIDS.

4. In order to aid the psychosocial adjustment of people living with HIV/AIDS, patients who have benefited from group counselling should be encouraged to bring along others known to be infected with the virus to attend group sessions. This will curb the spread of HIV.

\section{Counselling strategies}

During group counselling, the counsellor can assist the group by introducing to the people living with HIV/AIDS to the following strategies:

1. Rejection of negative thought: HIV/AIDS victims should be encouraged not to reflect on their past mistakes; not to live with regrets; not to see themselves as longer being useful to themselves and the society; not to see themselves as failures and disappointments, etc. During group counselling, they should be encouraged to discuss ways of living happily.

2. Use self-instruction: During group counselling patients should be made to understand that it is normal to fall into despair once in a while, but during that period they should encourage themselves, send encouraging messages to one another.

3. Practice optimism: Patients should be encouraged to see themselves as still having something positive to offer to the world despite their situation. The counsellor should try to inculcate in the patients the "we can do it feeling". "If others can do it, we can do it. HIV/AIDS is no barrier".

4. Resilience: HIV/AIDS patients should be encouraged to fight on by following medical advice to the later, seek for support from others where necessary. Those patients who do not like taking anti retroviral drugs should be encouraged by others to do so. They should be made to understand that it is a matter of taking the drugs to live in order to contribute their quota to the development of the society. Patients should be made to understand that positive attitude will affect them positively while negative attitude will affect them negatively. The ability to become strong, active, happy and successful lies with them. Group members can achieve this when they encourage themselves.

\section{Conclusion}

This study revealed that group counselling is an effective intersection for people living with HIV/AIDS. When experiences are shared, it helps patients to cope with their emotional responses. Group counselling helps patients in their psychosocial adjustment. As patients encourage one another, patients become proactive rather than reacting and feeling negatively about their situation. 


\section{References}

Akinade, E. A. (2012). Modern behaviour modification: Principles and practice. Ibadan: Bright Ways Publishers.

Akintoye, S. (1991). AIDS: Worries over measures. The Guardian Home-News 10, January 21.

Akpama, E. G. (2007). Perception of and attitude to HIV/AIDS preventive measures among adolescents in secondary school in Cross River State, Nigeria. unpublished Ph.D thesis, Faculty of Education, University of Calabar.

Cogan, L., Magongo, R. \& Lyanakga, U. (2002). Psychological aspects of HIV/AIDS. Curriculum for Health Professionals.

Delano, G. E. (2002). Answers to questions on HIV/AIDS. Ibadan: A.R.F.H Press.

Edu, E. E. (2012). Psychological adjustment of people living with HIV/AIDS in Yakurr local government area, Cross River State, Nigeria. Unpublished B.Sc. project, Cross River University of Technology, Calabar.

Egbule, J. F. (2009). Principles, techniques of behaviour modification. Benin City: Justice Jeco Press and Publishers Ltd.

Melgosa, J. (2008). Developing a healthy mind. A practical guide for any situation. Washington: Telleres Grajices Penelara.

Ndama, I. A. (2003). Minimizing the spread of HIV/AIDS among adolescents through counselling programmes. CASSON conference proceedings (12), 86-90.

Oshotimehin, I. E. (2003). Preventive behaviour education among secondary school adolescents living with HIV/AIDS. Journal of Nigerian School of Health 14 (4), 50-58. 
